\title{
Construção de práticas emancipatórias com conselheiros de saúde por meio de oficinas educativas e mapas conceituais
}

\author{
Construction of emancipatory practices with health councilors \\ through educational workshops and concept maps
}

Violeta Campolina Fernandes (https://orcid.org/0000-0001-5549-072X) ${ }^{1}$

Regina Stella Spagnuolo (https://orcid.org/0000-0002-6977-4165) ${ }^{1}$

${ }^{1}$ Faculdade de Medicina de Botucatu, Universidade Estadual Paulista. Av.

Prof. Montenegro s/n,

Rubião Junior. 18618-970

Botucatu SP Brasil.

vicampolina@gmail.com

\begin{abstract}
The aim of the study was to find out how community participation occurs within the scope of professional training of municipal health councilors through educational workshops and concept maps. This is a research-action, qualitative study, developed in three municipalities belonging to the Health Region of Cuesta Pole, São Paulo, Brazil, with 28 councilors. Educational workshops and concept maps were carried out and data were analyzed according to the dialogic thematic analysis and semiotic image analysis. The discussion was supported by the Significant Learning Theory. The results showed the importance of the Primary Health Care regarding qualified listening and health promotion and prevention actions. For the participants, exercising the role of councilor means being present at meetings and representing their segment to the population. They feel important as collaborators in the creation of public policies and assistance to other governing bodies related to budgetary and fiscal control. Educational workshops and concept maps were shown to be pedagogical strategies to be worked with health councilors, as they allowed moments of learning, exchanges of experiences, interaction and creation of bonds.
\end{abstract}

Key words Learning, Health councils, Health education, Social participation, Public health
Resumo Objetivou-se conhecer como se dá a participação comunitária no âmbito da capacitação profissional de conselheiros municipais de saúde por meio da realização de oficinas educativas e mapas conceituais. Trata-se de estudo qualitativo, do tipo pesquisa-ação, desenvolvido em três municípios pertencentes a Região de Saúde do Pólo Cuesta, São Paulo, Brasil, com 28 conselheiros. Foram realizadas oficinas educativas e mapas conceituais, sendo os dados avaliados conforme análise temática dialógica e análise semiótica de imagens. A discussão foi alicerçada pela Teoria da Aprendizagem Significativa. Os resultados evidenciaram a importância da Atenção Primária à Saúde no que se refere à escuta qualificada e às ações de promoção e prevenção da saúde. Para os participantes, exercer a função de conselheiro significa estar presente nas reuniões e representar seu segmento populacional. Sentem-se importantes como colaboradores na elaboração de políticas públicas e no auxílio a outros órgãos no controle orçamentário e fiscalizatório. Conclui-se que as oficinas educativas e os mapas conceituais se revelaram como estratégias pedagógicas a serem trabalhadas com conselheiros de saúde, uma vez que possibilitaram momentos de aprendizagem, trocas de experiências, interação e criação de vínculo.

Palavras-chave Aprendizagem, Conselhos de saúde, Educação em saúde, Participação social, Saúde pública 


\section{Introdução}

Como diretriz do Sistema Único de Saúde (SUS), a participação da comunidade é assegurada pela Lei $n^{\circ} 8.142 / 90$, tendo como instâncias colegiadas os conselhos e as conferências de saúde. Os conselhos de saúde são responsáveis por estratégias e pelo controle da execução da política de saúde, inclusive no que se refere aos aspectos econômicos e financeiros, sendo compostos por representantes do governo, prestadores de serviço, profissionais de saúde e usuários ${ }^{1}$.

Participar da formulação e do controle das políticas públicas exige empoderamento, autonomia, engajamento, conhecimento sobre as bases legais do sistema de saúde, definição de estratégias, capacidade de análise sócio-política para tomada de decisões, compreensão de conceitos, respeito ao próximo e boa comunicação, sendo muitas as dificuldades para efetivar o papel atribuído aos atores que participam dos conselhos de saúde.

Os principais entraves da participação comunitária estão relacionados à ausência de informações de saúde e conhecimento sobre o papel do conselheiro; irregularidades quanto à composição, posse e frequência das reuniões; falta de conhecimento para analisar a gestão financeira e prestação de contas; desinteresse da população para as questões coletivas e baixa motivação para participação ${ }^{2-6}$.

Deste modo, na perspectiva de fortalecer o exercício do controle social na política de saúde, faz-se necessário, por parte dos sujeitos políticos envolvidos, conhecerem efetivamente o SUS e sua legislação, seus paradigmas epidemiológicos, assistenciais, financeiros, políticos, culturais e sociais, visando ao acompanhamento e à avaliação do sistema de informações em saúde nos níveis municipal, estadual e federal. Assim, o aprendizado pode ser construído por meio de vivências em que ocorram interação dos sujeitos em busca do mesmo ideal.

Nesse sentido, iniciativas do Ministério da Saúde, como a edição das Portarias n ${ }^{\circ} 198$ de 2004 e $\mathrm{n}^{\circ} 1.996$ de 2007 , assumiu a responsabilidade da gestão com a formação de recursos humanos por meio da Educação Permanente em Saúde, em que ações de qualificações foram incorporados com a integração do ensino, serviço e comunidade, transformando as práticas profissionais e a organização do trabalho em uma perspectiva da problematização ${ }^{7,8}$.

Objetivando promover uma prática mais efetiva de conselheiros de saúde e fortalecer a demo- cracia participativa, foi criado em 2006 a Política Nacional de Educação Permanente para o Controle Social no SUS aprovada pelo Conselho Nacional de Saúde (CNS). Destacando iniciativas de educação para o controle social que contribuem para o desenvolvimento da ação do sujeito social, com metodologias participativas que valorizem as experiências das pessoas e que não estejam restritas aos conselhos e, portanto, envolvem toda a população nas melhorias do SUS9.

O grupo de trabalho da referida política transformou-se em Comissão Intersetorial de Educação Permanente para o Controle Social no SUS (CIEPCSS), por meio da Resolução n 374, de 14 de junho de 2007, com o objetivo de assessorar o CNS no acompanhamento da Política de Educação Permanente para o Controle Social no SUS em âmbito nacional, formar multiplicadores e formadores para o fortalecimento do controle social e articular uma rede nacional de educação permanente para o controle social ${ }^{10}$.

Necessita-se progressivamente estimular a autonomia dos cidadãos por meio de práticas emancipatórias, entendidas como aquelas que possibilitam contribuir e melhorar as condições de vida, responder criticamente e assumir a liberdade. Essas práticas ensinam os sujeitos a acessar direitos e a lutar por eles, incentivam valores de solidariedade e resgatam a condição humana como condição social ${ }^{11}$.

Com base nesse cenário, questiona-se: a realização de oficinas educativas resultou em aprendizagem significativa a partir da realidade vivenciada pelos conselheiros de saúde?

Este estudo teve como objetivo conhecer como se dá a participação comunitária no âmbito da capacitação profissional de conselheiros municipais de saúde por meio da realização de oficinas educativas e mapas conceituais.

\section{Método}

Trata-se de recorte de doutorado "Estratégias de mobilização para a participação comunitária de conselheiros municipais de saúde", alicerçado na pesquisa-ação, desenvolvido em três municípios pertencentes a Região de Saúde do Pólo Cuesta (RSPC) - Departamento Regional de Saúde (DRS) VI Bauru/ Rede Regional de Atenção à Saúde (RRAS) 9 - São Paulo, Brasil.

A RSPC é composta por 13 municípios compreendendo uma área territorial de $6.394,44 \mathrm{~km}^{2}$ e população de 279.329 habitantes $^{12}$. A escolha dessa região se deu por amostra não probabilísti- 
ca por conveniência uma vez que se buscou uma amostra da população que fosse mais acessível para o pesquisador.

Os critérios de seleção dos municípios foram de acordo com o perfil populacional, sendo: um município de pequeno porte 1 (MPP1), com até 20.000 habitantes, um de pequeno porte 2 (MPP2), de 20.001 até 50.000 habitantes e um de grande porte (MGP), de 100.001 até 900.000 habitantes.

Os participantes do estudo foram os conselheiros municipais de saúde, titulares e/ou respectivos suplentes, de três municípios da região de saúde do Pólo Cuesta, SP, e que concordaram em participar da pesquisa, após assinatura do Termo de Consentimento Livre e Esclarecido (TCLE), totalizando 28 conselheiros, 15 do MGP, 8 do MPP2 e 5 do MPP1.

Foram realizadas análises de documentos dos municípios e dos conselhos pertencentes à região de saúde do Pólo Cuesta e posteriormente oficinas educativas.

Esta análise permitiu a caracterização do município, sendo: a principal atividade desenvolvida, ramo de atividade predominante, população economicamente ativa, ano de criação e o regimento interno dos conselhos municipais de saúde. Esses dados foram solicitados às Secretarias Municipais de Saúde e também se recorreu a fontes secundárias, como as atas de reuniões dos conselhos, para complementar as informações do perfil do município e do conselho. Tal perfil foi necessário a fim de fundamentar a escolha dos temas e subsidiar as discussões durante as oficinas.

Para a criação das primeiras oficinas, foram colhidos temas propostos pelos participantes mediante realidade local vivenciada pelos mesmos. Os temas escolhidos das oficinas do MGP foram: "Organização e funcionamento do sistema de saúde"; "Planejamento em saúde: orçamento e financiamento"; "O controle das políticas e ações do SUS: mecanismos de acompanhamento, avaliação e fiscalização" e "Principais funções do conselheiro". No MPP2 os assuntos trabalhados foram: "Organização e funcionamento do sistema de saúde"; "Planejamento em saúde: orçamento e financiamento"; "O controle das políticas e ações do SUS: mecanismos de acompanhamento, avaliação e fiscalização". Já no MPP1 a escolha dos temas foram: "Planejamento em saúde: orçamento e financiamento"; "O controle das políticas e ações do SUS: mecanismos de acompanhamento, avaliação e fiscalização" e "Principais funções do conselheiro". Os dias, horários e frequência das oficinas foram pactuados de acordo com a disponibilidade dos participantes.
Foram realizadas 10 oficinas educativas sendo 4 no MGP, três no MPP1 e três no MPP2, no período de dezembro de 2016 a outubro de 2017 por meio de observação participante, diário de campo e mapas conceituais durante as oficinas educativas.

Oficina educativa caracteriza-se por um espaço de interação, reflexão e troca de conhecimentos que proporcionam ao educando expor e assimilar novos saberes sobre a temática em questão ${ }^{13}$. Ao final de cada oficina educativa utilizou-se o MC como medida de acompanhamento e avaliação da aprendizagem dos conselheiros.

Um MC é definido como um diagrama hierárquico com relações entre conceitos que possibilita a organização e a representação do conhecimento, com o objetivo de proporcionar maior compreensão e assimilação com o tema de estudo $^{14}$. Os MCs possuem conceitos, geralmente dentro de círculos ou quadros, e relações entre conceitos, que são representados por linhas que os interligam. As palavras sobre essas linhas, que são palavras ou frases de ligação, descrevem os relacionamentos entre os dois conceitos ${ }^{14,15}$.

Além disso, no MC há a presença de proposições, que são afirmações sobre objeto ou evento. Uma proposição é formada quando dois conceitos são interligados por meio de palavras, frases ou símbolos para compor uma afirmação significativa ${ }^{14}$.

A análise dos dados se deu segundo os pressupostos da análise temática dialógica de Bakhtin ${ }^{16}$ que propõe a definição de temas e a descrição dos processos dialógicos como uma maneira de entender as interações no momento da elaboração de informação, sendo extremamente dinâmico, flexível e não linear, juntamente com a análise semiótica da imagem parada ${ }^{17}$.

Para Penn ${ }^{17}$ a imagem em si é a descrição da mesma como é vista, ou seja, sua qualidade denotativa. Já a dimensão cultural dos elementos, que são as proposições formadas que integram a imagem, trata-se ao nível conotativo, ou seja, as relações existentes dos elementos com a conexão das palavras.

Foram utilizados diário de campo e observação das oficinas com a finalidade de analisar a produção que acompanha as imagens. A partir desse material foi interpretada a correlação entre o conhecimento científico e o aprendizado construído. Assim, no momento de análise da imagem, utilizou-se das histórias desenvolvidas pelos participantes para a compreensão das mesmas.

O referencial teórico utilizado partiu do pressuposto conceitual para o uso do MC da Teoria da Aprendizagem Significativa (TAS), do cons- 
trutivista David Ausubel ${ }^{18}$. A TAS propõe que, para um aprendizado mais eficiente, é necessário que o conhecimento seja compreendido, significativamente relevante e bem integrado ${ }^{14,18}$.

A aprendizagem significativa consiste na integração de novos conceitos à estrutura cognitiva do aprendiz, considerando o seu conhecimento prévio, com o objetivo de demonstrar aprendizagens inter-relacionadas, o que facilita o estabelecimento de associações conceituais sólidas ${ }^{18,19}$.

Ao final de cada oficina foram aplicados os MCs individuais e após o MC síntese pelo pesquisador, elaborado a partir das similaridades encontradas e repetições de palavras. A partir da realização de 10 oficinas educativas resultaram 63 MC individuais, sendo 32 do MGP, 19 do MPP2 e 12 do MPP1, que foram sintetizados um por município, com a finalidade de unir a produção individual e construir mapas sínteses sobre os significados que os participantes atribuíram em relação aos temas das oficinas. Dessa forma, revelou-se três MCs sínteses, um para cada município, contendo os significados atribuídos do aprendizado das oficinas.

Por último, aplicou-se uma nova síntese dos três mapas resultantes originando um novo mapa, chamado de mapa semiótico final contendo os dados mais significativos e suas principais relações de significados expressos pelos conselheiros.

O projeto foi aprovado pelo Comitê de Ética em Pesquisa com Seres Humanos da Faculdade de Medicina da Universidade Estadual Paulista "Júlio de Mesquita Filho" (UNESP), campus de Botucatu e possui financiamento pela Fundação de Amparo à Pesquisa do Estado de São Paulo - FAPESP. O estudo foi realizado mediante autorização do Secretários Municipais de Saúde e após consentimento dos participantes por meio da assinatura do TCLE.

\section{Resultados}

A idade dos 28 participantes variou entre 22 e 70 anos, sendo a idade média de 45 anos. Quanto ao sexo, $71,42 \%$ eram do feminino e $28,58 \%$ do masculino. Quanto à escolaridade, $39,28 \%$ possuíam ensino superior completo, $28,58 \%$ ensino médio completo, $25 \%$ pós-graduação e $7,14 \%$ ensino fundamental completo. A profissão ou estado referido que mais se destacou foi aposentado (14,29\%).

Em relação à representatividade nos conselhos municipais de saúde (CMS), 42,85\% representam os usuários dos serviços de saúde, $21,45 \%$ os prestadores de serviço, $17,85 \%$ os trabalhadores da saúde e $17,85 \%$ os gestores.

No que diz respeito a aprendizagem evidenciada nas oficinas educativas do MGP, a Figura 1 significa os conceitos chaves que mais apareceram juntamente com as palavras de ligação utilizadas pelos conselheiros (Figura 1).

$\mathrm{O}$ número de conceitos incluídos no $\mathrm{MC}$ síntese foi de 61, relativos aos conceitos subordinados ao geral: "Organização e funcionamento do sistema de saúde", "Orçamento", "Relatório de Gestão" e "Papel do conselheiro".

Em relação a estrutura do mapa, $100 \%$ foram diagramados em forma sequencial com hierarquia e formação de algumas ligações cruzadas.

A maioria das proposições apresentaram significados lógicos, sendo que as palavras selecionadas para inter-relacionar os conceitos mostraram-se adequadas para conhecer as nuances dos significados atribuídos na sistematização do conhecimento.

Importante observar que o conceito "Esclarecer a população" foi o mais citado (nove vezes) nos MCs individuais, seguido de "Aprovação no CMS" e "Controle dos gastos da saúde" (ambos sete vezes), evidenciando a relevância que os conselheiros atribuem em relação a disseminação de informações para a população sobre os temas de saúde e na função de aprovar e controlar os gastos da saúde ${ }^{20}$.

Verifica-se um domínio dos conselheiros com as temáticas trabalhadas, uma vez que os MCs realizados permitiu visualizar a integração dos conteúdos abordados nas oficinas, ou seja, à medida que um novo conceito chave foi aprendido, este foi integrado ao MC de forma coerente e harmônica. Além disso, percebe-se uma interação, colaboração e comprometimento dos conselheiros com a realização dos MCs, uma vez que as dúvidas e dificuldades foram sanadas com outros membros do grupo, evidenciando o trabalho em equipe ${ }^{20}$.

Entretanto, sete MCs não apresentaram as palavras de ligação e alguns conceitos estavam sem relações e repetitivos, principalmente nos primeiros mapas, o que pode ser justificado por ser o primeiro contato com a ferramenta de aprendizagem.

O número de conceitos incluídos no MC síntese do MPP2 (Figura 2) foi de 53, relativos aos conceitos subordinados ao geral: "Problemas na organização e funcionamento da saúde", "Orçamento", "Financiamento" e "Fiscalização da gestão no CMS".

O MC síntese possui uma ramificação a partir do conceito raiz até seis níveis hierárquicos, 


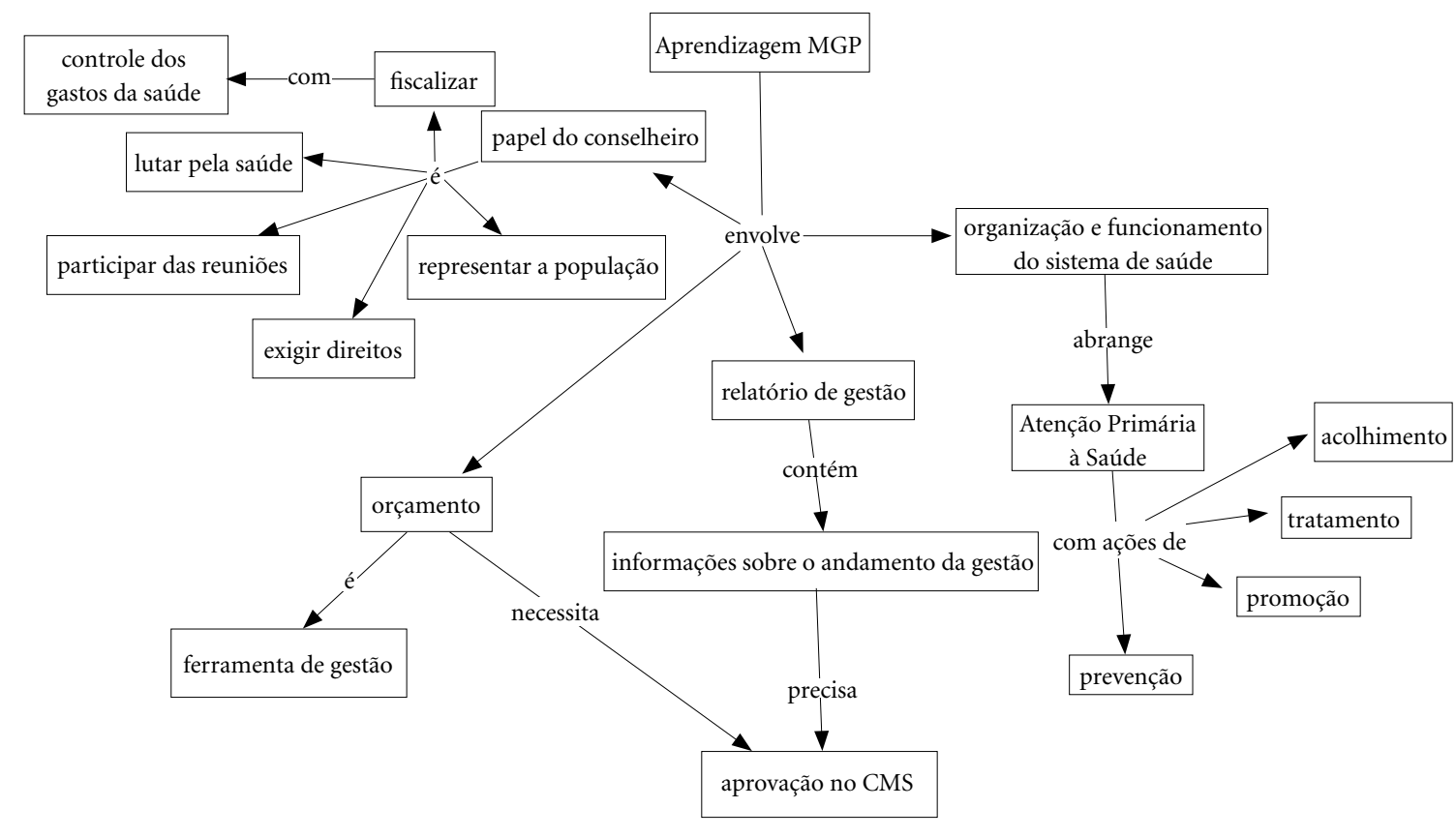

Figura 1. Mapa conceitual síntese do MGP, Botucatu, SP, Brasil, 2019.

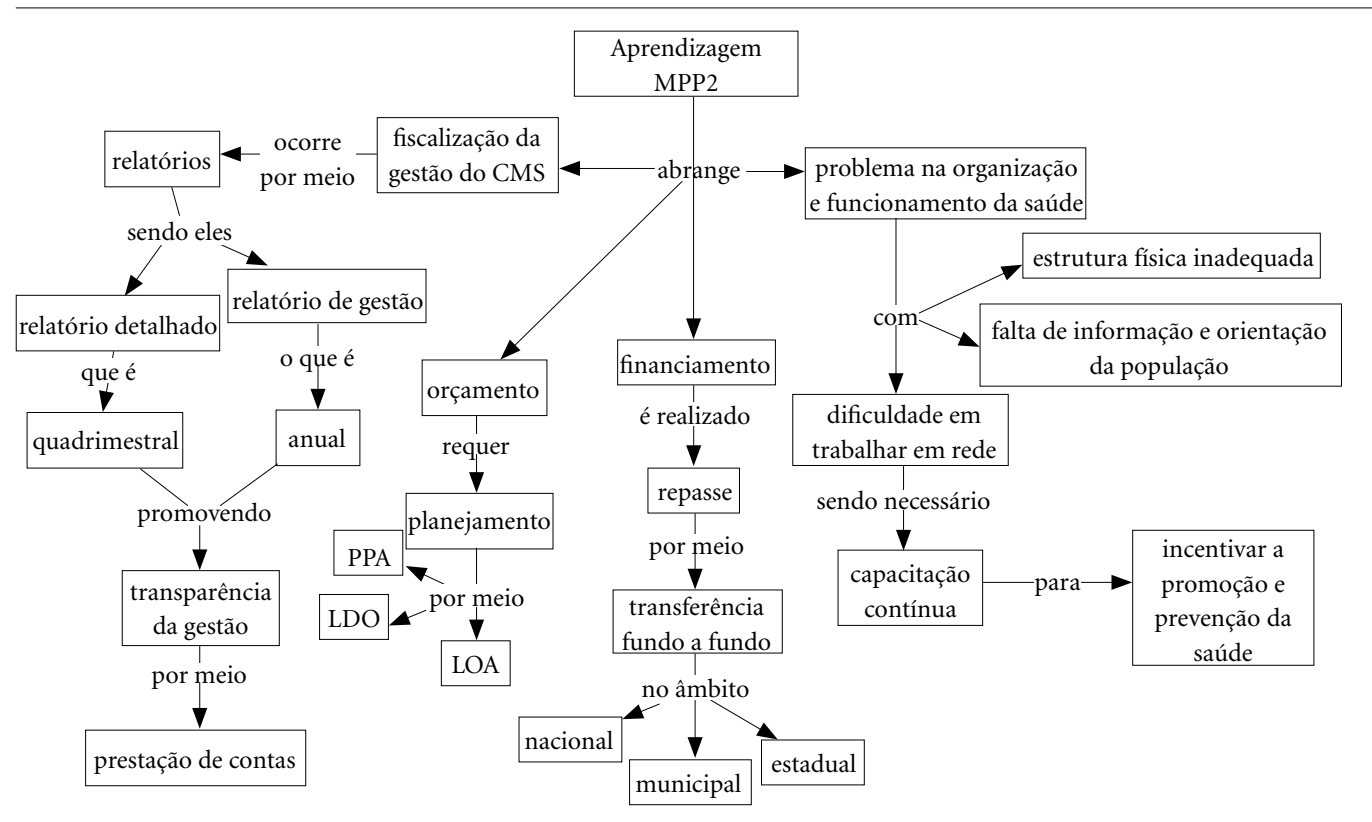

Figura 2. Mapa conceitual síntese do MPP2, Botucatu, SP, Brasil, 2019.

que configuram os conceitos dos mais gerais até os mais específicos, passando por diferentes níveis de conceitos intermediários e quatro ligações cruzadas, sendo os conceitos e as proposições formadas $100 \%$ em forma sequencial.
Algumas proposições elencadas foram relevantes, visto que os membros não possuíam familiaridade com os temas, como exemplo, a proposição formada por: o "orçamento requer planejamento por meio Lei Orçamentária Anual 
(LOA), Lei de Diretrizes Orçamentárias (LDO) e Plano Plurianual (PPA)", "financiamento é realizado por repasse por meio da transferência fundo a fundo no âmbito municipal, estadual e nacional", "fiscalização da gestão no CMS ocorre por meio de relatório sendo eles o relatório de gestão que é anual promovendo a transparência da gestão por meio da prestação de contas".

Percebe-se que os conselheiros fazem referência ao modelo orçamentário brasileiro, as leis orçamentárias, ao financiamento e à fiscalização da saúde o que gerou aprendizagem significativa, uma vez que com base na observação participante e no diário de campo da pesquisadora, antes da realização das oficinas, os conselheiros não conheciam esses conceitos.

O conceito "Falta de informação e orientação da população" foi o mais citado (oito vezes) nos MCs individuais, seguido de "Incentivar a promoção e prevenção da saúde", "Planejamento" e "Transparência da gestão" (ambos quatro vezes), demonstrando a conscientização que os conselheiros têm de que a população necessita receber mais informações sobre as ações de saúde, sendo necessário o incentivo por parte dos conselheiros, gestores e profissionais da promoção e prevenção da saúde. Além disso, pode-se observar o destaque que os participantes deram para o fato de o orçamento acontecer com o seu devido planejamento e o conselheiro possuir como função primordial a fiscalização por meio da transparência da gestão para assim realizar o controle social.

O MC síntese do MPP1 (Figura 3) possui 35 conceitos, com os conceitos subordinados ao geral: "Relatório de gestão", "Papel do conselheiro" e "Orçamento e financiamento".

Dispõe de conceitos dentro da caixa, interligados por meio de palavras de ligação, uma ramificação a partir do conceito raiz, até cinco níveis hierárquicos, e duas ligações cruzadas, sendo os conceitos e as proposições formadas $100 \%$ em forma sequencial.

O conceito "Verificar o andamento da saúde" foi o mais citado (cinco vezes) nos MCs individuais, seguido de "Realizar o controle e fiscalizar" (quatro) e "Transparência" (três). Verifica-se que os conceitos mais presentes referem principalmente ao papel do CMS na gestão do SUS, relacionados à participação da sociedade no processo de fiscalização dos recursos e andamento dos trabalhos realizados pela gestão de saúde com transparência.

Esses conceitos foram mais marcantes devido principalmente aos conselheiros serem em sua maior parte trabalhadores da saúde, com conhe- cimento da nomenclatura das ações realizadas. Entretanto, apesar de entenderem o vocabulário, as siglas e as demais atividades que são da realidade participativa, desconhecem a fundo as legislações, os prazos e as metas.

Pode-se observar na maioria dos mapas uma preocupação com as palavras de ligação, seleção dos conceitos e a formação das proposições. À medida que a oficina foi avançando, os conceitos tornaram-se mais elaborados e os conselheiros gradativamente foram melhorando a formulação do MC, exercitando a criatividade e a reflexão do conhecimento adquirido.

A partir da realização da síntese dos mapas conceituais, a estratégia utilizada para nortear a discussão foi inter-relacionar os três MCs síntese a fim de criar um único mapa que represente o aprendizado vivenciado nas oficinas educativas, em que se buscou analisa-lo à luz da aprendizagem significativa de David Ausubel ${ }^{18}$. Assim, revelou-se um mapa semiótico final (Figura 4) contendo os dados considerados mais relevantes e as principais relações de significados expressos pelos conselheiros.

Pode-se compreender a partir da síntese dos mapas, a interação entre o aprendizado de todos os membros que emergiram das experiências vividas das oficinas educativas e, como resultado final, um novo mapa semiótico. Essa estratégia possibilitou desvelar os significados atribuídos pelos participantes em relação aos temas por eles escolhidos.

O mapa semiótico final demonstra como os conselheiros compreendem os conteúdos retratados nas oficinas educativas. Ele possui 49 conceitos dispostos dentro das caixas, interligados por meio de palavras de ligação, três ramificações a partir do conceito raiz, até sete níveis hierárquicos e duas ligações cruzadas, sendo os conceitos e as proposições apresentados em forma sequencial.

Apresenta-nos que o contexto da construção do conhecimento envolve três significados importantes, chamados por Ausubel et al..$^{21}$ de conceitos mais inclusivos, sendo eles: atenção à saúde, fiscalização e papel do conselheiro (Figura 5).

O conceito "Atenção à saúde" reúne os significados construídos sobre a saúde pública brasileira, em que se pode identificar a percepção dos conselheiros sobre a organização e o funcionamento do sistema de saúde. Assim, esse conceito apresenta diferentes significados que vão desde os conceitos mais abrangentes até os menos inclusivos, sendo os mais abrangentes: a) A Atenção Primária à Saúde como estratégia de organização 


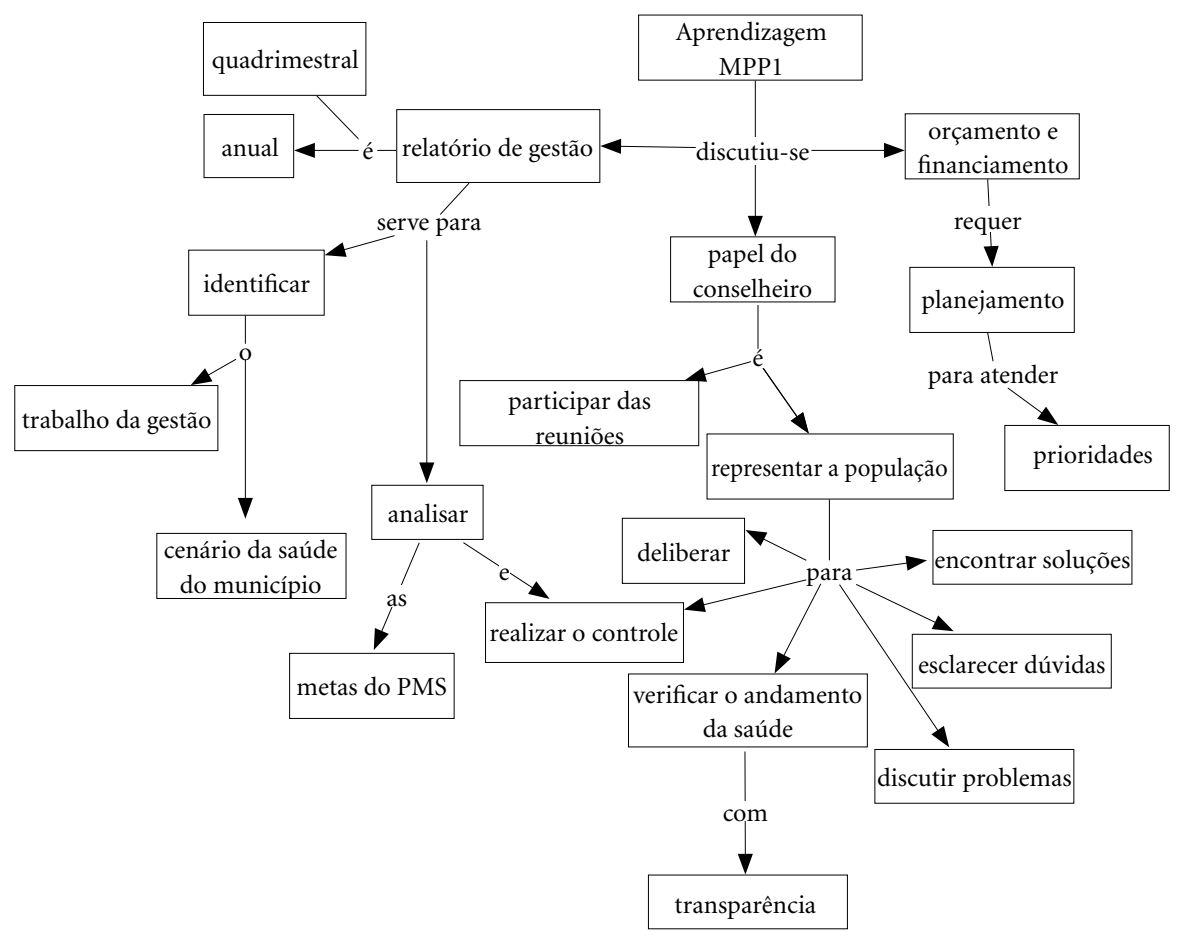

Figura 3. Mapa conceitual síntese do MPP1, Botucatu, SP, Brasil, 2019.

da atenção à saúde e b) Os entraves da atenção à saúde ${ }^{20}$.

A Atenção Primária à Saúde (APS) ou Atenção Básica $(\mathrm{AB})$ tem como estratégia fundamental a reorganização e a articulação dos recursos disponíveis no SUS com o propósito de atender as demandas e as necessidades da população e inserir-se no contexto da rede de atenção à saúde ${ }^{22}$.

Estrutura-se como primeiro ponto de atenção e principal porta de entrada aberta do sistema, sendo ordenadora de fluxos e contrafluxos e coordenadora das ações e serviços disponibilizados pela rede ${ }^{23}$.

Assim, os conselheiros entendem a APS como estratégia de organização da atenção à saúde com ações de promoção, prevenção, acolhimento e tratamento, em que a prevenção aos agravos e a escuta qualificada devem ocorrer nos modelos de atenção à saúde de forma efetiva, garantindo ao usuário o atendimento necessário ao seu problema, evitando a superlotação do pronto socorro e possibilitando o trabalho em rede ${ }^{20}$.

Percebe-se a partir da proposição acima que o armazenamento de informações dos conselhei- ros foi organizado e hierarquizado, na medida que elementos mais específicos de conhecimentos foram ligados e assimilados a conceitos mais gerais, assim como propõe Ausubel ${ }^{18,24}$.

\section{Discussão}

Observa-se por meio dos MCs a importância que os conselheiros dão para APS, principalmente a realização da escuta qualificada, de forma que seja identificada a necessidade do usuário e que o atendimento seja realizado com ações de promoção e prevenção da saúde, não ficando restrito à consulta médica ${ }^{20}$.

Essa compreensão vai ao encontro da Política Nacional de Atenção Básica (PNAB), que retrata que os serviços devem assegurar acessibilidade e acolhimento de forma organizada, garantindo que todas as pessoas que procurem os serviços sejam ouvidas de modo universal e sem diferenciações ${ }^{23}$.

Assim sendo, os serviços de saúde devem assumir a função central de acolher, escutar, e resolver a maioria dos problemas da população, 


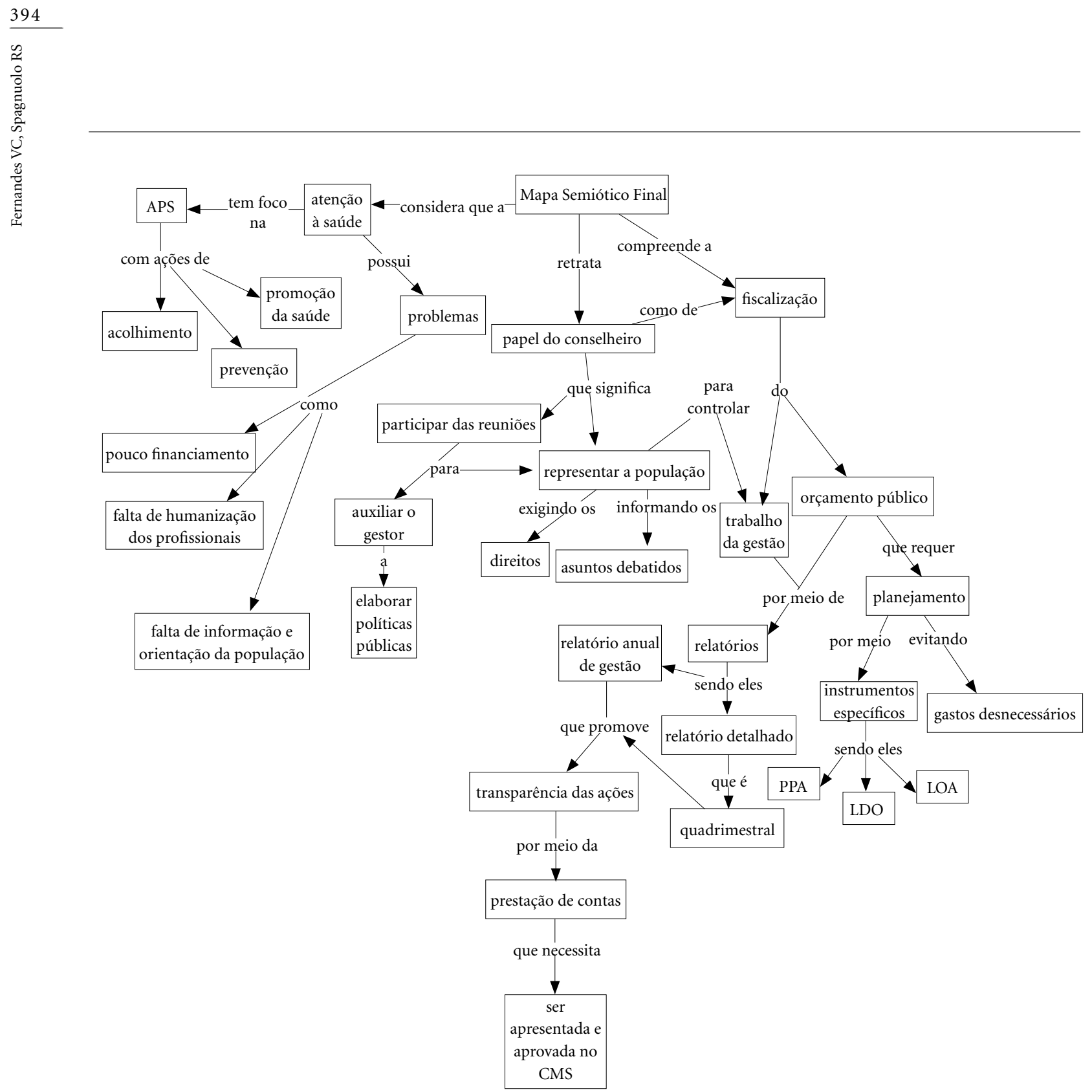

Figura 4. Mapa Semiótico Final. Botucatu, SP, Brasil, 2019.

amenizando os danos e os sofrimentos com busca da integração da rede de atenção à saúde ${ }^{23}$.

Em continuidade, os conselheiros apontam os principais entraves da atenção à saúde: a falta de informação e orientação da população, a falta de humanização dos profissionais e o pouco financiamento para a saúde ${ }^{20}$.

A proposição formada por "mapa semiótico final considera que a Atenção à saúde possui problemas como a falta de informação e orientação da população sendo necessário divulgar os serviços existentes e esclarecer a população" está de acordo com estudo que aponta uma dificuldade de entendimento das variáveis que interferem na saúde e doença, bem como do funcionamento do sistema de saúde por uma parcela da comunidade, sendo necessário a criação de estratégias de comunicação com essa população para aprimorar a atenção prestada ${ }^{25}$.

No que diz respeito à relação do usuário com o profissional de saúde, evidenciou-se a falta de humanização dos profissionais, apontando a necessidade de capacitação contínua. Desta maneira, há de se refletir sobre as condições de trabalho 


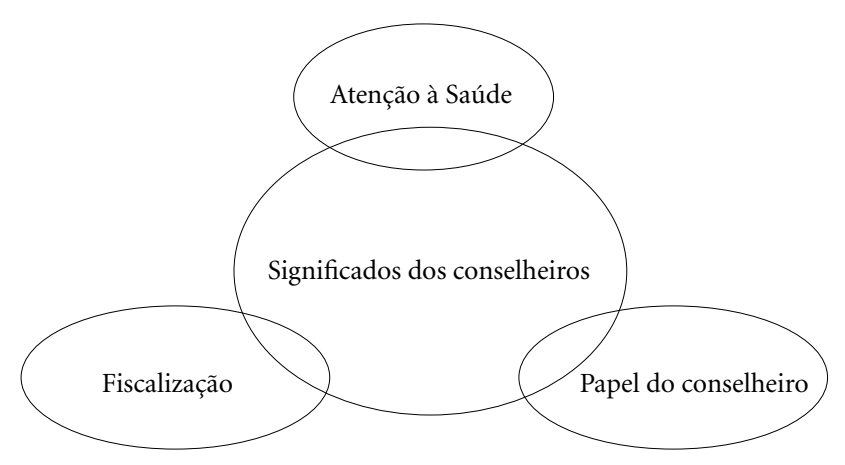

Figura 5. Significados dos conselheiros sobre o aprendizado das oficinas educativas, Botucatu, SP, Brasil, 2019.

dos profissionais de saúde, se estes se encontram em condições de garantir um atendimento humanizado, uma vez que, geralmente, são submetidos a processos de trabalhos mecanizados e encontram-se fragilizados pelas condições de sobrecarga, formas de contratação, rotatividade e convívio com o sofrimento e morte ${ }^{26}$.

Desse modo, algumas ações mostram-se cruciais para a melhoria do acesso e humanização, são elas: estabelecimento de parcerias com órgãos formadores, construção de linhas de cuidado, incentivo à participação ativa dos profissionais nas políticas, promoção de reuniões entre seus pares para reflexão prática (estudos de caso, situações problema), atividades de educação permanente, entre outras.

Destaca-se ainda o conceito "pouco financiamento para saúde" demonstrando a compreensão dos conselheiros com o processo de desenvolvimento do SUS, a forma com que o repasse é realizado - por meio da transferência fundo a fundo, e da crise que o país atravessa devido ao subfinanciamento da saúde.

Destaca-se, ainda, o conceito "pouco financiamento para saúde", demonstrando a compreensão dos conselheiros com o processo de desenvolvimento do SUS, a forma com que o repasse é realizado - por meio da transferência fundo a fundo aos Estados, Distrito Federal e Municípios, conforme a Portaria $n^{\circ} 3.992$, que dispõe sobre o financiamento, sob responsabilidade das três esferas de gestão e a transferência dos recursos federais para ações e serviços públicos de saúde do SUS 27 .

Para viabilizar o SUS é necessário garantir financiamento suficiente e permanente, entretanto, a Emenda Constitucional 95/16 congela os gastos públicos por vinte anos, sem apreciar as transformações demográficas, epidemiológicas e a necessidade de inclusão de tecnologias no SUS. Diante desse cenário, torna-se crucial a mobilização da população a favor da luta pela democracia e justiça social, para que a saúde esteja incluída na pauta do debate político nacional ${ }^{28}$.

Pode-se dizer que os conselheiros organizaram o conhecimento das oficinas a partir de representações concisas das estruturas conceituais que lhes foram ensinadas e que provavelmente facilitaram a aprendizagem dessas estruturas como propõe a Teoria da Aprendizagem Significativa de Ausubel.

Segundo Ausubel ${ }^{18}$, a estruturação do conhecimento verifica-se de modo não arbitrário, pela recepção de novas informações, o que possibilita ao aprendiz interioriza-las tornando-as mais compreensíveis. Assim, os conceitos interagem com os novos conteúdos, auxiliando para a atribuição de novos significados que também se modificam. Essa modificação contínua vai tornando um subsunçor, isto é, o conhecimento prévio, mais elaborado, mais diferenciado, capaz de servir de âncora para a aquisição de novos conhecimentos, sequencia chamada de diferenciação progressiva.

$\mathrm{Na}$ aprendizagem significativa ocorre uma mudança da nova informação e também no conhecimento prévio com o qual o novo conhecimento estabelece relação, sendo que o produto dessa interação é a incorporação de significados e exteriorização do conhecimento ${ }^{21}$ como evidenciado no mapa semiótico final.

Ainda, o mapa semiótico final, revelou-se mais uma vez, a compreensão dos participantes ao exercer a função de conselheiro municipal de 
saúde, que significa estar presente nas reuniões dos CMS para auxiliar o gestor a elaborar políticas públicas e representar a população informando os assuntos debatidos e exigindo os direitos dos usuários do SUS.

Os conselhos de saúde têm atribuições legais e específicas de controle social. A sua responsabilidade é a de contribuir para a formação de conselheiros comprometidos com a construção da política, baseada nos direitos à cidadania de toda a população, em defesa da vida e da saúde, com acesso universal, integral e igualitário ${ }^{9}$, pois, são os representantes da sociedade, que deverão comandar o processo participativo, a voz representativa da população para formular e fiscalizar a saúde.

O mapa semiótico final apresentou a proposição formada por: a fiscalização do orçamento público e o trabalho da gestão ocorre por meio de relatórios, sendo eles Relatório anual de gestão e o Relatório detalhado, que promovem a transparência das ações da gestão por meio da prestação de contas que necessita ser apresentada e aprovada no CMS, para melhor exercício do controle social.

Os conselheiros reconheceram o importante papel que possuem no auxílio a outros òrgãos, na fiscalização e no controle do orçamento público. No entanto, por meio da observação participante notou-se que esse processo ainda é deficiente uma vez que ocorre de maneira rápida e não planejada ${ }^{20}$.

É extremamente importante que o conselheiro de saúde tenha acesso a essas informações com antecedência, para analisar e criticar adequadamente e, ainda, divulgue na sociedade, fazendo com que o usuário seja corresponsável, por meio de uma gestão participativa ${ }^{20}$.

Ainda, no que diz respeito ao orçamento público, as proposições elencadas foram extremamente relevantes, visto que os conselheiros não possuíam familiaridade com o tema. Como exemplo, tem-se a proposição formada por: "Mapa semiótico final compreende a fiscalização do orçamento público que requer planejamento com responsabilidade evitando gastos desnecessários por meio de instrumentos específicos, sendo elas Plano Plurianual (PPA), Lei de Diretrizes Orçamentárias (LDO) e Lei Orçamentária Anual (LOA)", percebe-se que os conselheiros fazem referência ao modelo orçamentário brasileiro e às leis orçamentárias utilizadas para o planejamento dos recursos públicos ${ }^{20}$.

O PPA tem por finalidade essencial estabelecer de forma regionalizada as diretrizes, os obje- tivos e as metas da administração pública federal adequado às despesas de capital e delas decorrentes e para as relacionadas aos programas de duração continuada ${ }^{29}$.

Cabe à LDO definir as metas e as prioridades da adiminsitração pública e orientar a elaboração da LOA, que tem como principal atribuição fixar as metas fiscais ${ }^{30}$.

Evidenciou-se as novas ideias e informações que foram aprendidas na estrutura cognitiva do indivíduo, uma vez que os conceitos formados foram relevantes, inclusivos e claros.

O compartilhamento de vivências, enquanto forma de significar os assuntos debatidos, foi extremamente importante para possibilitar a aprendizagem signiticativa, uma vez que o diálogo criado e a exposição de experiências complementaram-se e relacionaram-se ao conhecimento prévio dos indivíduos.

Enfim, podemos inferir, com esses resultados, que o trabalho contribuiu para o avanço da ciência, pois foi capaz de fomentar aos participantes novos saberes acerca de temas importantes do campo da saúde, colocando-os como protagonistas no processo de aprendizagem. Esse fato oportunizou a troca de saberes, vivências, sentimentos e experiências, estimulando-os a uma participação da comunidade de forma emancipatória, crítica e reflexiva ${ }^{20}$.

Espera-se que os resultados possam ser replicados nas diferentes realidades de conselhos municipais de saúde a fim de estimular e dar visibilidade à participação comunitária enquanto uma diretriz do SUS. Importa, ainda, que gestores municipais e universidades incorporem a participação comunitária nos seus espaços de debates, estimulando a participação da sociedade civil organizada por meio dos conselheiros de saúde, potencializando um melhor controle social.

Como fatores limitantes, apresenta-se a resistência de alguns conselheiros quanto à participação nas oficinas educativas, resultando em aprendizado difereciado para os membros do grupo, uma vez que aqueles que participaram dos encontros puderam vivenciar reflexões e mudanças sobre a prática exercida.

\section{Considerações finais}

As oficinas educativas e os mapas conceituais revelaram-se como excelentes estratégias pedagógicas a serem trabalhadas com conselheiros municipais de saúde uma vez que possibilitaram momentos de aprendizagem, trocas de experiên- 
cias, interação e estabelecimento de vínculo entre os participantes.

O espaço grupal e a confecção dos mapas conceituais possibilitaram a explicitação de ideias, conhecimentos prévios, momentos de conexões, relações, trocas, visões de mundo diferentes para cada um dos conselheiros e a oportunidade de construção do conhecimento individual e coletivo, melhorando, dessa forma, a atuação dos conselheiros e, por desdobramento, aumentando a visibilidade da participação da comunidade enquanto diretriz do SUS.

A análise dos dados por meio da Análise Temática Dialógica e Análise Semiótica da Imagem Parada permitiram dinamicidade à análise e à construção de um mapa semiótico final que materializasse os significados construídos pelos conselheiros em relação à temas do campo da saúde.

\section{Colaboradores}

VC Fernandes participou da concepção do estudo, realização da pesquisa, análise dos dados, redação e revisão crítica do manuscrito. RS Spagnuolo participou da concepção do estudo, análise dos dados, redação e revisão crítica do manuscrito. 


\section{Referências}

1. Brasil. Lei $\mathrm{n}^{\circ} 8.142$, de 28 de dezembro de 1990. Dispõe sobre a participação da comunidade na gestão do Sistema Único de Saúde (SUS) e sobre as transferências intergovernamentais de recursos financeiros na área da saúde, e dá outras providências. Diário Oficial da União 1990; $31 \mathrm{dez}$.

2. Bispo-Júnior JP, Sampaio, JJC. Participação social em áreas rurais do Nordeste do Brasil. Rev Panam Salud Publica 2008; 23(6):403-409.

3. Flores W, Gómez-Sánchez I. La gobernanza en los Consejos Municipales de Desarrollo de Guatemala: Análisis de actores y relaciones de poder. Rev Salud Pública 2010; 12(1):138-150.

4. Rocha CV. Gestão pública municipal e participação democrática no Brasil. Rev. Sociol. Polit. 2011; 19(38):171-185.

5. Shimizu HE, Pereira MF, Cardoso AJC, Bermudez XPCD. Representações sociais dos conselheiros municipais acerca do controle social em saúde no SUS. Cien Saude Colet 2013; 18(8):2275-2284.

6. Busana JA, Heidemann ITSB, Wendhausen ALP. Participação popular em um conselho local de saúde: limites e potencialidades. Texto Contexto Enferm 2015; 24(2):442-449.

7. Brasil. Portaria $n^{\circ} 198$, de 13 de fevereiro de 2004 . Institui a Política Nacional de Educação Permanente em Saúde como estratégia do Sistema Único de Saúde para a formação e o desenvolvimento de trabalhadores para o setor e dá outras providências. Diário Oficial da União 2004; 13 fev.

8. Brasil. Portaria $\mathrm{n}^{\circ} 1.996$, de 20 de agosto de 2007. Dispõe sobre as diretrizes para a implementação da Política Nacional de Educação Permanente em Saúde. Diário Oficial da União 2007; 20 ago.

9. Conselho Nacional de Saúde (CNS). Política Nacional de Educação Permanente para o Controle Social no Sistema Único de Saúde - SUS. Brasília: Editora do Ministério da Saúde; 2006.

10. Brasil. Resolução ${ }^{\circ}$ 374, de 14 de junho de 2007. Diário Oficial da União 2007; 14 jun.

11. Campos CMS, Silva BRB, Forlin DC, Trapé CA, Lopes IO. Práticas emancipatórias de enfermeiros na Atenção Básica à Saúde: a visita domiciliar como instrumento de reconhecimento de necessidades de saúde. Rev Esc Enferm USP 2012; 48(n. esp.):119-125.

12. São Paulo. Diretoria Regional de Saúde 6 (DRSIV). Mapa da Saúde do Pólo Cuesta. Bauru: DRSIV; 2012.

13. Freire P. Pedagogia do Oprimido. $17^{\mathrm{a}} \mathrm{ed}$. Rio de Janeiro: Paz e Terra; 1987.

14. Novak JD, Cañas AJA. Teoria subjacente aos mapas conceituais e como elaborá-los e usá-los. Práxis Educativas 2010; 5(6):9-29.

15. Moreira MA, Masini EFS. Aprendizagem significativa: a teoria de David Ausubel. 2a ed. São Paulo: Centauro; 2006.

16. Bakhtin M. Estética da criação verbal. São Paulo: Martins Fontes; 1992.

17. Penn G. Análise semiótica de imagens paradas. Pesquisa qualitativa com texto, imagem e som. Um manual prático. Petrópolis: Vozes; 2003.

18. Ausubel DP. Aquisição e retenção de conhecimentos: uma perspectiva cognitiva. Lisboa: Plátano; 2003.
19. Souza NA, Boruchovitch E. Mapas conceituais: estratégia de ensino/aprendizagem e ferramenta avaliativa. Educ. Rev 2010; 26(3):195-218.

20. Fernandes VC, Spagnuolo RS. Pesquisa-ação como caminho de mobilização à participação comunitária nos conselhos municipais de saúde. In: Atas do $7^{\circ}$ Congresso Ibero-Americano de Investigação Qualitativa em Saúde; 2018; Fortaleza. p. 18-27.

21. Ausubel DP, Novak JK, Hanesian H. Psicologia Educacional. $2^{a}$ ed. Rio de Janeiro: Interamerica Ltda; 1980.

22. Mendes E. A construção social da atenção primária à saúde. Brasília: CONASS; 2015.

23. Brasil. Portaria $\mathrm{n}^{\circ} 2.436$ de 21 de setembro de 2017. Aprova a Política Nacional de Atenção Básica, estabelecendo a revisão de diretrizes para a organização da Atenção Básica no âmbito do Sistema Único de Saúde (SUS). Diário Oficial da União 2007; 21 set.

24. Moreira MA. Teorias de Aprendizagem. $2^{\mathrm{a}}$ ed. São Paulo: EPU; 2011.

25. Viegas APB, Carmo RF, Luz ZMP. Fatores que influenciam o acesso aos serviços de saúde na visão de profissionais e usuários de uma unidade básica de referência. Saude Soc 2015; 24(1):100-112.

26. Goulart BNG, Chiari BM. Humanização das práticas do profissional de saúde - contribuições para reflexão. Cien Saude Colet 2010; 15(1):255-268.

27. Brasil. Portaria $\mathrm{n}^{\circ} 3.992$, de 28 de dezembro de 2017. Altera a Portaria ${ }^{\circ}$ 6/GM/MS, de 28 de setembro de 2017, para dispor sobre o financiamento e a transferência dos recursos federais para as ações e os serviços públicos de saúde dos Sistema Único de Saúde. Diário Oficinal da União 2017; 28 dez.

28. Reis AAC. O que será do Brasil e do SUS? Rev Eletron Comum Inf Inov Saúde 2018; 12(2):119-124.

29. Brasil. Constituição da República Federativa do Brasil de 1988. Diário Oficial da União 1988; 5 out.

30. Culau AA, Fortis MFA. Transparência e controle social na administração pública brasileira: avaliação das principais inovações introduzidas pela lei de responsabilidade fiscal. In: XI Congresso Internacioal del CLAD sobre la Reforma del Estado y de la Administración Pública; 2006; Cidade de Guatemala. p. 1-16.

Artigo apresentado em 12/03/2020

Aprovado 25/04/2020

Versão final apresentada em 27/04/2020

Editores-chefes: Maria Cecília de Souza Minayo, Romeu Gomes, Antônio Augusto Moura da Silva 